\title{
Nieuw rumoer rond Moses Shapira's 'Deuteronomium'
}

\author{
K. van Bekkum
}

\begin{abstract}
This article offers a short overview and assessment of the debate regarding the so-called Shapira manuscripts which came to light in the 1880s, following the publication of an article and monograph by Idan Dershowitz, professor of Hebrew Bible at the University of Potsdam. Claiming the manuscripts Moses Shapira tried to sell to the British Museum in 1883 were not forgeries, Dershowitz argues that they were a pre-exilic earlier version of the canonical Deuteronomy. The article reviews the history of reception of the manuscripts in view of methodological and societal issues.
\end{abstract}

\section{De 'Shapira Affair' (1878-1890)}

Sinds half maart 2021 is de wereld van de oud-Hebreeuwse epigrafie, Qumran en het onderzoek naar Deuteronomium in rep en roer. Aanleiding is de volgende ronde in de zogenoemde 'Shapira Affair', naar Moses Wilhelm Shapira (1830-1884), een Poolse Jood die vanuit Kamenets-Podolski in het huidige Oekraïne naar Jeruzalem emigreerde, zich onderweg in Boekarest bekeerde tot het christelijk geloof en in 1861 een antiquiteitenhandel begon in de christelijke wijk van de Oude Stad. Hij gold als autoriteit, onder meer op het terrein van middeleeuwse en vroegmoderne Joodse geschriften uit het MiddenOosten. Via zijn winkel vonden vele oudheden hun weg naar musea in Parijs, Londen en Berlijn.

De behoefte aan oudheden bij de onderling concurrerende koloniale machten in het Westen was zo groot dat Salim al-Khouri, een Arabische gids en kenner van oude inscripties, een productielijn van (veelal erotische) figuren met inscripties opzette die gevonden zouden zijn aan de overkant van de Jordaan en die via Shapira werden verkocht. In 1873 werd al-Khouri echter ontmaskerd door Charles Simon Clermont-Ganneau (1846-1923), een Franse geleerde en diplomaat die in 1868 met hem had samengewerkt rond de vondst van de Mesasteen. Deze beroemde stèle van de Moabitische koning Mesa uit Diban was uiteindelijk door de clans in de regio in stukken verkocht en na veel gedoe in het Louvre terechtgekomen. De Duitse kopers van de meeste 'Moabitica' voor het Vorderasiatisches Museum in Berlijn gaven overigens pas 
in 1876 toe dat men met vervalsingen te maken had, terwijl Konstantin Schlottmann, voorzitter van de Deutsche Morgenlandische Gesellschaft, bleef geloven dat in elk geval een deel van de verzameling echt was. ${ }^{1}$

Groot was daarom de spanning, toen Moses Shapira in 1883 in Londen verscheen met zestien opgevouwen stukjes leer met oud-Hebreeuws schrift dat leek op dat van de Mesasteen. Samen bevatten de fragmenten twee manuscripten van een veel kortere versie van het boek Deuteronomium. Was dit wel echt? Waren de strips de gevraagde één miljoen pond waard? Al in 1878 had Shapira Schlottmann een kopie van de strips gezonden. De oudtestamenticus Franz Delitzsch had destijds echter onmiddellijk geconcludeerd dat het een vervalsing betrof. ${ }^{2}$ Een paar weken voor zijn bezoek aan Londen had Shapira het opnieuw geprobeerd en Halle en Leipzig aangedaan, nu met de strips zelf. Maar Duitse geleerden, onder wie Hermann Guthe (1849-1936), die zijn bevindingen kort daarop publiceerde, concludeerden dat het een vervalsing betrof. ${ }^{3}$

In Londen was het oordeel in eerste instantie positief. Duizenden bezoekers, onder wie premier William Gladstone, verdrongen zich rond twee tentoongestelde strips in het British Museum. Nadere inspectie door onder meer de Britse geleerde Christian David Ginsburg (1831-1914) én ClermontGanneau, die de strips van Shapira eerst niet had mogen zien, resulteerde echter in de omgekeerde conclusie. ${ }^{4}$ Het leer leek afgesneden van een Jemenitische rol, het schrift was afgekeken van de Mesasteen en de tekst bevatte een 'verchristelijkte' versie van Deuteronomium (inclusief de Tien Woorden, maar zonder de wet van Deuteronomium 12-26). Een regelrechte vervalsing dus.

De maanden daarop kocht het British Museum nog boeken van Shapira. Blijkbaar keek niet iedereen hem persoonlijk aan op het fiasco. Tegelijk vroeg hij zich af of hij de schande die hem hiermee was aangedaan wel zou overleven. Een antisemitische cartoon in het blad Punch liet zien welke onderliggende sentimenten meespeelden. Ginsburg en Shapira waren beiden tot het

1 Martin Heide, 'The Moabitica and their Aftermath: How to Handle a Forgery Affair with an International Impact', in: Meir Lubetski (red.), New Inscriptions and Seals Relating to the Biblical World (Archaeology and Biblical Studies 19), Atlanta 2012, 193-241.

2 Vgl. Franz Delitzsch, 'Schapira's Pseudo-Deuteronomium', Allgemeine EvangelischLutherische Kirchenzeitung (1883), 843-846, 870-872, 894, 915-916.

3 Hermann Guthe, Fragmente einer Lederhandschrift enthaltend Mose's letzte Rede an die Kinder Israel, Leipzig 1883.

4 'The Shapira Manuscripts', Palestine Exploration Quarterly Statement 1883, 195-209. Op 25 augustus 1883, een week voor het rapport uitkwam, publiceerde Ginsburg zijn transcriptie en vertaling als 'The Shapira Ms. of Deuteronomy', Athenaeum PEQS (1883), 242-244. 
christelijk geloof bekeerde Joden van Poolse afkomst en lid van de Anglicaanse Kerk. De eerste was echter 'een van de onzen' en zijn ontmaskering werd beleefd als een symbool van de superioriteit van de Britse bestudering van bijbelse oudheden. ${ }^{5}$ De van fraude verdachte Shapira werd daarentegen voorzien van een stereotyperende zwarte hoed, een baard en een haakneus. Hij vertrok naar Europa en pleegde op 8 maart 1884 zelfmoord in een hotel bij de Rotterdamse Willemsbrug. Precies zes jaar later verkocht het Londense handelshuis Quaritch de gevouwen strips voor tien pond en vijf shilling aan Philip Brooks Mason, een arts uit het Engelse Burton-on-Trent. Tot op de dag van vandaag zijn ze niet teruggezien.

\section{Qumran}

Hoewel Shapira uiteenlopende verhalen had verteld over hoe de strips hem hadden bereikt, waren ze volgens hem gevonden in een grot aan de overkant van de Jordaan, ten zuiden van het gebergte tegenover Qumran. Geen wonder dat na de vondst van de Dode Zee-rollen sommigen zich de Shapirateksten herinnerden. Zo kwam het linnen omhulsel rond de strips dat in 1883 aanleiding was geweest ze te zien als een vervalsing, ook in Qumran voor. Eind jaren vijftig pleitte onder meer Menachem Mansoor daarom voor nieuwe bestudering van de tekeningen en transcripties die van de teksten waren gemaakt. ${ }^{6}$

Sindsdien werd in academische wandelgangen het vermoeden soms geuit dat de Shapirastrips authentiek zouden zijn. Hoe gevoelig dit lag, bleek in 1965, toen de Britse Qumran-specialist John Allegro dit verdedigde in een boek en hierom en om nog andere buitenissige ideeën zijn universitaire loopbaan vaarwel moest zeggen. ${ }^{7}$

De laatste jaren gonst het weer rond Shapira. In een fraaie documentaire over de affaire, Shapira and I. In the Footsteps of Shapira and his Scroll (2014) achterhaalde de Isrälische journalist en regisseur Yoram Sabo wie de nog altijd onvindbare strips kocht en waar Shapira in Rotterdam begraven ligt. ${ }^{8}$ In 2016 publiceerde journalist Chanan Tigay een fascinerend verslag van een

5 Fred N. Reiner, 'C.D. Ginsburg and the Shapira Affair: A Nineteenth-Century Dead Sea Scroll Controversy', British Library Journal 21 (1995), 109-127.

6 Menahem Mansoor, 'The Case of Shapira's Dead Sea (Deuteronomy) Scrolls of 1883', Transactions of the Wisconsin Academy of Sciences, Arts and Letters 47 (1958), 183-229.

7 John Allegro, The Shapira Affair, Garden City 1966; vgl. Judith Anne Brown, John Marco Allegro: The Maverick of the Dead Sea Scrolls, Grand Rapids 2005.

8 Beschikbaar via https://vimeo.com/99821693 [geraadpleegd op 30 juni 2021]. 
zoektocht waarin hij de Jemenitische rol meent te hebben achterhaald waarvan de strips zijn afgesneden. ${ }^{9}$ Shlomo Guil, onafhankelijk archeologisch onderzoeker, nam het een jaar later op voor Mansoors gedachte dat de tekst een extra Dode Zee-rol betrof. ${ }^{10}$ En begin 2021 kwam Ross K. Nichols, docent in de Hebreeuwse Bijbel, met een boek dat de authenticiteit van de tekst verdedigt. ${ }^{11}$

\section{'Oerversie van Deuteronomium'}

Bewoog dit gesprek over de Shapirastrips zich nog aan de randen van de academie, met de publicaties van Idan Dershowitz, Joods-Amerikaans hoogleraar Hebrew Bible in Potsdam bij Berlijn, kwam dit anders te liggen. Hij heeft de eerste weergave van de oud-Hebreeuwse fragmenten door Shapira teruggevonden. Mee op basis daarvan publiceerde hij op 10 maart 2021 in open access hierover een monografie en een samenvattend artikel - beide bij gezaghebbende Duitse wetenschappelijke uitgevers. ${ }^{12}$ Als klap op de vuurpijl verscheen tevens een prachtig vormgegeven stuk in de New York Times. ${ }^{13}$ De conclusies van Dershowitz liegen er niet om. Volgens hem waren de Shapirateksten authentiek en betreft het geen verkorte versie van het boek Deuteronomium, maar de oerversie daarvan ergens uit de 8ste eeuw v.Chr. De vondst zou bovendien recente theorieën bevestigen over latere toevoegingen aan het boek. ${ }^{14}$

9 Chanan Tigay, The Lost Book of Moses: The Hunt for the World's Oldest Bible, New York 2016.

10 Shlomo Guil, 'The Shapira Scroll was an Authentic Dead Sea Scroll', Palestine Exploration Quarterly 149 (2017), 6-27.

11 Ross K. Nichols, The Moses Scroll: Reopening the Most Controversial Case in Biblical Scholarship, Saint Francisville 2021.

12 Idan Dershowitz, The Valediction of Moses: A Proto-Biblical Book (Forschungen zum Alten Testament 145), Tübingen 2021. Beschikbaar via DOI 10.1628/978-3-16-160645-8; Idan Dershowitz, 'The Valediction of Moses: New Evidence on the Shapira Deuteronomy Fragments', Zeitschrift für die alttestamentliche Wissenschaft 133 (2021), 1-22. Beschikbaar via https://doi.org/10.1515/zaw-2021-0001 [geraadpleegd 30 juni 2021].

13 Jennifer Schuessler, 'Is a Long-Dismissed Forgery Actually the Oldest Known Biblical Manuscript?', New York Times, 10 maart 2021. Beschikbaar via https://www.nytimes.com/ 2021/03/10/arts/bible-deuteronomy-discovery.html [geraadpleegd 30 juni 2021].

14 Met name een voorstel uit 2002 dat Deut. 1:22-25 is toegevoegd (ontbreekt ook in Shapira's 'Deuteronomium') en de mogelijke verplaatsing van de Ebal en Gerizim naar de Jordaanvallei in de Qumrantekst 4QJoz (wat ook zou gebeuren in Shapira's 'Deuteronomium' in Deut. 27). Dershowitz, Valediction, 63-68, 91-92. 
Ten slotte biedt Dershowitz een geannoteerde reconstructie en vertaling van de tekst, die hij het 'Afscheid van Mozes' noemt: een tekst zónder de wetten van Deuteronomium 12-26, met fragmenten uit hoofdstuk 1-4; in hoofdstuk 5 een versie van de Tien Woorden helemaal in de ik-vorm, en een elfde gebod, ' $U$ zult in uw hart uw broeder niet haten, Ik ben Elohim, uw God'; verder kleine stukjes uit hoofdstuk 6-11; en een andere versie van hoofdstuk 27 met tot slot verzen uit hoofdstuk 28 en 30.15

\section{Waardering en verbijstering}

Direct na de publicatie waren de bewondering en verbijstering online tastbaar. De ontdekking van Shapira's eigen weergave van de teksten is hoe dan ook winst. Shapira lijkt daarin fouten te maken die later niet meer werden gemaakt. Dit suggereert dat de tekst ook voor hem nieuw was. Verder is er alom lof voor de wetenschappelijke editie van de tekst. Dat helpt bij het voeren van het kritische gesprek erover. Ook de observatie dat tekenaars in het British Museum letters soms beter hebben weergegeven dan bijvoorbeeld Ginsburg, helpt bij de reconstructie van de tekst. Of het ook de kwaliteit van Ginsburgs transcriptie ondergraaft, is een andere vraag.

Verder overheerst echter de verbazing. Waarom zou opnieuw iemand zijn carrière schaden aan wat eerder overduidelijk een vervalsing bleek? Wat beweegt prestigieuze Duitstalige bijbelwetenschappers en uitgevers om hier gewicht aan toe te kennen? In 2020 moesten onderzoekers van naam en uitgeverij Brill een publicatie terugtrekken, omdat de fragmenten van Dode Zeerollen die erin bestudeerd worden, vals bleken te zijn. ${ }^{16}$ Vooral onderzoekers in de traditie van de Amerikaanse epigrafie reageerden direct afwijzend. De originele Shapirateksten zijn verdwenen. Het schrijfmateriaal dateren met de $\mathrm{C}_{14}$-methode, de letters beter belichten, of met een microscoop achterhalen of de inkt later op verweerd leer is aangebracht - het is allemaal niet meer mogelijk. Er is daarom geen enkele reden terug te komen op het oordeel van kenners die de fragmenten wél hebben gezien. Christopher Rollston vatte

15 Dershowitz' vertaling is beschikbaar via https://gist.github.com/michaelt/8189b2937070c4 ba76b40248805d9eda [geraadpleegd 30 juni 2021].

16 Emanuel Tov, Kipp Davis, en Robert Duke (red.), [Retracted] Dead Sea Scrolls Fragments in the Museum Collection (Publications of the Museum of the Bible 1), Leiden/Boston 2016, retraction notice. Beschikbaar via https://brill.com/view/title/33413 [geraadpleegd 30 juni 2021]. 
de afwijzing direct samen in een blogpost. ${ }^{17}$ Twee maanden later volgde Matthieu Richelle, een Franse epigraaf uit de school van Clermont-Ganneau, met een sympathiek getoonzet, maar uitgebreid kritisch stuk dat alle bezwaren nog eens rustig op een rij zet. ${ }^{18}$

Intussen passeerden ook andere aspecten de revue: hoe Shapira's verkorte Deuteronomium zou passen bij opvattingen onder laat 19de-eeuwse bekeerde Joden, ${ }^{19}$ de verwantschap tussen de weergave van zegen en vloek in Deuteronomium 27 in Shapira's Deuteronomium en rabbijnse bronnen, ${ }^{20}$ en de hoge frequentie van afwijkende werkwoordsvormen. ${ }^{21}$

17 Christopher Rollston, 'Deja Vu all over Again: The Antiquities Market, the Shapira Strips, Menahem Mansoor, and Idan Dershowitz', 10 maart 2021. Beschikbaar via http://www. rollstonepigraphy.com/?p=896 [geraadpleegd 30 juni 2021]. Zie ook Maria Metzler, 'Christopher Rollston's Critique of the Shapira Argument by Idan Dershowitz' (beschikbaar via https://www.academia.edu/45519388/Christopher_Rollston_s_Critique_of_the_ Shapira_Argument_by_Idan_Dershowitz) en de reacties daarop: http://www.rollstone pigraphy.com/?p=896\#comments [geraadpleegd 30 juni 2021].

18 Matthieu Richelle, 'The Shapira Strips in Light of Paleography' (te publiceren in Semitica): https://www.academia.edu/48905750/The_Shapira_Strips_in_Light_of_Paleography_ forthcoming_in_Semitica [geraadpleegd 30 juni 2021].

19 Jonathan Klawans, 'The Shapira Fragments: An Artifact of 19th-Century Jewish Christianity'. Beschikbaar via https://www.biblicalarchaeology.org/daily/the-shapira-fragments/ [geraadpleegd 30 juni 2021].

20 Meir Bar-Ilan, אריפש לש הליגמה לע ץיבושרד 'ע :רפס תרוקיב (te publiceren in Zeitschrift für altorientalische und biblische Rechtsgeschichte). Beschikbaar via https://www.academia. edu/46930440/Review_by_Meir_Bar_Ilan_of_Dershowitz_on_Shapirah [geraadpleegd 30 juni 2021].

21 Benjamin D. Suchard, 'The Valediction of Moses Is Not a Proto-Deuteronomy: Evidence From the Verbal System'. Beschikbaar via https://www.academia.edu/46783534/The Valediction_of_Moses_is_not_a_proto_Deuteronomy_evidence_from_the_verbal_system, en de reacties daarop: Idan Dershowitz en Na'ama Pat-El, 'Response to Benjamin Suchard, "The 'Valediction of Moses' Is Not a Proto-Deuteronomy: Evidence From the Verbal System"'. Beschikbaar via https://www.academia.edu/47094146/Response_to_Benjamin_ Suchard_The_Valediction_of_Moses_is_not_a_proto_Deuteronomy_evidence_from_the verbal_sys-tem_en Harald Samuel, 'A Reply to Idan Dershowitz and Na'ama Pat-El's "Response to Benja-min Suchard”'. Beschikbaar via https://www.academia.edu/48837407/ Sam-uel_2021_Reply_to_Dershowitz_and_Pat_El_[geraadpleegd 30 juni 2021]. 


\section{Nieuwe argumenten}

De discussie roept de vraag op welke nieuwe argumenten Dershowitz aandraagt. Zijn eerste punt betreft de oud-Hebreeuwse letters jod en he op de strips, die destijds werden gezien als bewijs van vervalsing. Vanwege latere vondsten zou het oordeel van de huidige epigrafie anders moeten luiden. Vooralsnog overtuigt dit veel epigrafen niet. Richelle benadrukt dat losse waarnemingen vragen om een breder methodologisch perspectief. Dan blijft de he merkwaardig en lijkt de jod te veel op al-Khouri's afschrift van de Mesastèle. Bovendien lijken de afwijkende zayin, kaf, qof, en șade opvallend veel op die van de Moabitica. Dit alles is het gemakkelijkst te verklaren als resultaat van een laat-19de-eeuwse vervalsing. ${ }^{22}$

Een tweede argument heeft te maken met de wordingsgeschiedenis van het boek Deuteronomium. Volgens Dershowitz ligt het 'Afscheid van Mozes' erg dicht bij een eerdere versie van Deuteronomium, zoals die door sommige geleerden wordt gereconstrueerd. Verder staan diverse verwijzingen naar de Tien Woorden in het Oude Testament, bijvoorbeeld 'meineed plegen' in Jeremia 7:9, dichter bij Shapira's Deuteronomium dan bij Deuteronomium 5, in dit geval vers 11. Dat zou bewijzen dat die andere teksten niet naar Deuteronomium verwijzen, maar naar het 'Afscheid van Mozes'. Dershowitz maakt in zijn monografie veel werk van dit argument. Hij kondigt zelfs aan zo nog meer puzzels rond het ontstaan van de Bijbel te zullen oplossen. Het punt is alleen wel dat hij, zoals in Duitsland gebruikelijk, zijn uitgangspunt niet neemt in het boek Deuteronomium zoals dat er ligt, maar in de door onderzoekers gereconstrueerde vorm van dat boek. Dat maakt het geheel wankel: hier worden immers niet teksten met elkaar vergeleken die echt bestaan, maar twee teksten (het 'Afscheid van Mozes' en een vroegere versie van Deuteronomium) die het resultaat zijn van (theoretische) reconstructie door bepaalde onderzoekers. Bovendien ziet deze manier van werken voorbij aan lastige elementen in het 'Afscheid van Mozes'. Daarin is bijvoorbeeld onhelder waar Mozes nu precies zijn vaarwel uitspreekt en hoe Israël daar gekomen is, terwijl het begin van Deuteronomium er glashelder over is. ${ }^{23}$

22 Richelle, 'Shapira Strips', 3-20. Volgens de Amerikaanse epigraaf Ron Hendel wijst ook het gebruik van leesmoeders in de tekst daarop. Ron Hendel, 'Notes on the Orthography of the Shapira Manuscripts: The Forger's Marks', Zeitschrift für die alttestamentliche Wissenschaft 133 (2021), 225-230.

23 Een ander voorbeeld is Mozes' gebod om de wet te lezen op de Ebal en de Gerizim (Deut. 27). Shapira's 'Deuteronomium' lijkt deze bergen naar het zuiden te verplaatsen. Volgens Dershowitz wordt dat bevestigd door de verplaatsing van de bergen in 1QJoz ${ }^{\text {a }}$. Dit is echter niet het geval. De uitvoering van Mozes' gebod in Jozua 8:30-35 staat in de Qumran-tekst 
$\mathrm{Nu}$ is het verstandig geen enkele mogelijkheid bij voorbaat uit te sluiten. Maar om de relatie tussen het 'Afscheid van Mozes' en Deuteronomium echt onafhankelijk te testen, is het eigenlijk nodig een paar opties uit te werken en die met elkaar te vergelijken: (1) de tekst is ontstaan uit Deuteronomium; (2) het omgekeerde is het geval; (3) beide gaan terug op nog weer een andere tekst. Pas dan kun je kijken welke oplossing het meeste recht doet aan de teksten zoals ze nu zijn. ${ }^{24}$

Een laatste argument biedt Dershowitz samen met Na'ama Pat-El, een taalkundige van de universiteit van Austin, Texas. Volgens hen wijzen schrijfwijze, woordgebruik en grammatica erop dat de tekst op de strips Hebreeuws is van voor de ballingschap. Ook hier zijn echter diverse bezwaren tegen ingebracht. Zo leidt het ontbreken van leesmoeders ertoe dat soms ook een verdubbelde jod is gesneuveld die er toch hoort te staan - wat nauwelijks anders te verklaren is dan door een vervalsing. Verder wijst de vaak voorkomende węqātal voor de verleden tijd in passages die niet parallel lopen met Deuteronomium op een auteur die vertrouwd is met nabijbels Hebreeuws. ${ }^{25}$

\section{Tragiek}

Het nieuwe rumoer rond Shapira's Deuteronomium zit deels vast op de gebruikte methode. Wie de bestaande teksten als uitgangspunt neemt, begrijpt goed waarom veel epigrafen en historici verontwaardigd zijn dat hier oud fake news nieuw leven wordt ingeblazen. In de Duitstalige bijbelwetenschap is het gebruikelijker te werken op basis van gereconstrueerde bronnen. Wie dat zelf ook doet, zal de hypothese van Dershowitz meer het overwegen

inderdaad op een andere plek, namelijk na Jozua 5:1. De Septuaginta heeft de tekst op nog weer een andere plaats, namelijk achter 9:1. Maar dit impliceert nog geen andere geografie. Niet de bergen, maar de tekst wordt verplaatst, terwijl in alle gevallen het aardrijkskundige probleem hetzelfde blijft: terwijl Jozua en Israël in Gilgal gelegerd zijn, volgt ineens een korte scene op een andere plaats.

24 Optie (1) is uitgewerkt in de slotanalyse van Benjamin D. Suchard, 'A Valediction to Moses W. Shapira's Deuteronomy document' (te publiceren in Bibliotheca Orientalis), 5-15, beschikbaar via https://www.academia.edu/48862842/A_valediction_to_Moses_W_ Shapira_s_Deuteronomy_document [geraadpleegd 30 juni 2021].Z.i. zijn de meeste afwijkingen van Deuteronomium eenvoudig te verklaren als harmoniserende lezingen en grijpt Shapira's 'Deuteronomium' terug op de masoretische tekst van het Oude Testament.

25 Zie de literatuur in noot 22 en Suchard, 'Valediction to Moses W. Shapira's Deuteronomy', $15-25$. 
waard vinden. ${ }^{26}$ Vooralsnog lijkt het er vanuit literair-historisch perspectief echter niet op dat het aangedragen bewijs sterk genoeg is om de verstrekkende beweringen te staven. Een boek Deuteronomium zonder de wetgeving van hoofdstuk 12-26 is nauwelijks voorstelbaar. Bovendien zijn de vervloekingen aan het slot van Shapira's Deuteronomium in vergelijking met andere oudoosterse verdragen erg kort en hangen ze zonder de wetgeving in de lucht. ${ }^{27}$

Voorbij de methodische kwestie is het wetenschapstheoretisch gezien beter de kwestie van de authenticiteit van de tekst te benaderen vanuit het niet meer beschikbaar zijn van de strips en vanuit de nog voorhanden data: de vorm van de overgeleverde letters en de taal. De bezwaren op dit terrein van met name Richelle en Benjamin Suchard liegen er niet om. Zelfs als een deel ervan kan worden weerlegd, blijft de conclusie dat het negatieve oordeel van eerdere generaties epigrafen en hebraïsten eerder is versterkt dan verzwakt. Als het klopt dat Shapira's Deuteronomium door twee auteurs is geschreven, ligt het in het licht van de kennis van deze schrijvers van de toenmalige epigrafie, de bijbelse teksten, het nabijbels Hebreeuws en de rabbijnse traditie voor de hand dat niet al-Khouri, maar twee anderen de tekst hebben vervaardigd. Daarbij komen uiteraard Shapira zelf en wellicht ook een door hem genoemde dr. Landsberg als verdachten in beeld. ${ }^{28}$

26 Zie echter de kritische opmerkingen van Eckart Otto m.b.t. de literaire methode van Dershowitz in Eckart Otto, 'Review of Idan Dershowitz, The Dismembered Bible: Cutting and Pasting Scripture in Antiquity, Forschungen zum Alten Testament 143, Tübingen 2021', Zeitschrift für altorientalische und biblische Rechtsgeschichte 27 (2021). Beschikbaar via https://www.academia.edu/45549976/Eckart_Otto_Review_of_Idan_Dershowitz_The_ Dismembered_Bible_Cutting_and_Pasting_Scripture_in_Antiquity_FAT_143_T\%C3\%BC bingen_2021_ZAR_27_2021_[geraadpleegd 30 juni 2021]. Tijdens 'A Scholarly Webinar on Idan Dershowitz' Recent Reassessment of the Shapira Documents' op 10 juni 2021, georganiseerd door Daniel Stökl Ben Ezra van de École Pratique des Hautes Études te Parijs, wees Konrad Schmid (redacteur van de reeks waarin Dershowitz zijn monografie heeft gepubliceerd) erop dat het debat z.i. geen 'ja-nee-kwestie' betreft. Wel ligt het literairkritisch meer voor de hand dat de Tien Woorden in Shapira's Deuteronomium niet voorafgaan aan, maar zijn afgeleid van de bijbelteksten.

27 Zie m'n 'Biblical Covenants and Treaties in Ancient Near Eastern Context: A Methodological, Historical and Theological Reassessment', in: Hans Burger, Gert Kwakkel en Michael Mulder (red.), Covenant - A Vital Element in Reformed Theology: Biblical, Historical and Systematical Perspectives (Studies in Reformed Theology), Leiden (te verschijnen).

28 Vgl. Ross K. Nichols, 'Moses Shapira's Letter to Hermann Strack'. Beschikbaar via https:// www.academia.edu/48769937/Moses_W_Shapiras_Letter_to_Hermann_Strack [geraadpleegd 30 juni 2021]. 
Tegelijk is het goed in de gaten te houden dat in de hele controverse een ander element een rol speelt: de antisemitische sfeer die in 1883 hielp om Shapira's vondst in diskrediet te brengen. In dat licht is het begrijpelijk dat vandaag de dag zowel Joodse onderzoekers als niet-Joodse Duitstalige bijbelwetenschappers huiverig zijn pleidooien voor de echtheid van zijn vondst al te gemakkelijk af te serveren en liever ruimte geven aan een scherp inhoudelijk debat. Dat debat is er nu. Bij alle waardering van de critici voor Dershowitz' vakmanschap en creativiteit misschien zelfs sneller dan de redacteuren en uitgevers van de publicaties hadden voorzien. Dat is mooi, maar het heeft ook iets tragisch dat juist door deze discussie net als bij de Moabitische figuren in 1873 het resultaat lijkt te worden dat men (te) laat moet toegeven dat het een vervalsing betreft.

K. van Bekkum is hoogleraar Oude Testament aan de Evangelische Theologische Faculteit, Leuven en doceert tevens aan de Theologische Universiteit Kampen. 